\title{
Vantagem competitiva: um estudo sobre recursos e capacidades estratégicos em empresas de cervejas artesanais
}

\author{
Julianne Ferraz Alonso Martins* \\ Cleiciele Albuquerque Augusto**
}

\begin{abstract}
RESUMO
O presente estudo teve como objetivo compreender, à luz da Visão Baseada em Recursos (VBR), como os recursos e capacidades estratégicos influenciam na vantagem competitiva em cervejarias artesanais na cidade de Maringá. Para tanto, foram coletados dados através de entrevistas semiestruturadas com sócios das empresas, sendo tratados e interpretados por meio do método de análise de conteúdo. Os resultados obtidos revelam que os recursos distintivos das empresas investigadas consistem, sobretudo, em recursos físicos e organizacionais. Observou-se que os recursos físicos contribuem para a eficiência da produção e, consequentemente, para a qualidade do produto. Por sua vez, os recursos organizacionais contribuem no desempenho das organizações no sentido de as empresas apresentarem estratégias mais robustas para atingir seu foco. Assim, conclui-se que os recursos e capacidades distintos influenciam o desempenho da organização e geram vantagens para suas respectivas empresas.
\end{abstract}

Palavras-chave: Visão Baseada em Recursos. VRIO. Vantagem Competitiva. Cervejarias Artesanais.

\section{COMPETITIVE ADVANTAGE: A STUDY ON STRATEGIC RESOURCES AND CAPACITIES IN HANDICRAFT BEER COMPANIES}

\begin{abstract}
The present study aimed to understand, in the light of the Resource Based View (VBR), how strategic resources influence competitive advantage in artisanal breweries in the city of Maringá. For this, data were collected through semi-structured interviews with partners of the companies, being treated and interpreted through the content analysis method. The results reveal that the distinctive resources of the investigated companies consist, above all, of physical and organizational resources. It was observed that physical resources contribute to production efficiency and, consequently, to product quality. In turn, organizational resources contribute to the performance of organizations
\end{abstract}

* http://orcid.org/0000-0001-5416-3217. Universidade Estadual de Maringá (UEM). Graduada em Administração pela Universidade Estadual de Maringá. E-mail: caaugusto2@gmail.com .

** http://orcid.org/0000-0001-5416-3217. Universidade Estadual de Maringá. Professora Adjunta do Departamento de Administração da Universidade Estadual de Maringá. Atua na área de Estratégia Organizacional e Gestão de Pessoas. E-mail: cleicielealbuquerque@yahoo.com.br . 
in the sense that companies present more robust strategies to achieve their focus. Thus, it is concluded that the different resources and capacities influence the performance of the organization and generate advantages for their respective companies.

Keywords: Resource Based View. VRIO. Competitive advantage. Craft Breweries.

\section{INTRODUÇÃo}

A VBR é um modelo de desempenho com foco nos recursos e capacidades controlados pela empresa, os quais são fontes de vantagem competitiva (TEECE; PISANO; SHUEN, 1997; BARNEY; HESTERLY, 2012). Nessa linha, uma empresa obtém vantagem competitiva quando é capaz de utilizar seus recursos para gerar maior valor econômico em relação aos seus concorrentes (BARNEY; HESTERLY, 2012). Segundo Barney (1991) e Barney e Hesterly (2012), os recursos e capacidades podem ser divididos em quatro categorias: recursos financeiros, físicos, humanos e organizacionais. Para identificar, analisar e potencializar esses recursos, Barney e Hesterly (2012) propõem o Modelo VRIO, que indica que os recursos da firma devem conter quatro atributos importantes para explorar seu potencial de gerar vantagem: serem valiosos, raros, difíceis de imitar e organizados.

É notório que recursos estratégicos podem ser uma forma de gerar vantagem competitiva em ambientes de concorrência. Essa situação tem sido observada no setor de cervejarias artesanais que tem se expandido de forma evidente nos últimos anos. Anteriormente, esse mercado era dominado por marcas de cervejas tradicionais e existiam poucas opções alternativas. Com isso, empreendedores enxergaram oportunidades e investiram nesse segmento, oferecendo um produto e serviço diferenciado e com maior valor agregado para os consumidores.

Corroborando com esta crescente tendência do setor, a última atualização do Ministério da Agricultura, Pecuária e Abastecimento (MAPA) informa que a região Sul conta com o maior número de cervejarias do país. Segundo o MAPA (2018), a cidade de Maringá conta com quatro cervejarias artesanais registradas, e algumas aguardando registros fabris e alvarás. De acordo com dados do NUCEM (Núcleo Cervejeiro de Maringá) (2018), a cidade produz cerca de 165 mil litros por mês $(1 / \mathrm{m})$, o que tem levado a cidade de Maringá ao topo dos pódios nacionais.

Diante desse contexto, observa-se, por um lado, uma oferta crescente em relação à instalação de novas cervejarias artesanais. Por outro, questiona-se se essas empresas têm conhecimento sobre seus recursos e capacidades como fontes de vantagem para competir no setor. A partir dessa problemática, levantou-se a seguinte questão de pesquisa: Como os recursos e capacidades estratégicos influenciam na vantagem competitiva em empresas de cervejas artesanais na cidade de Maringá? Portanto, o objetivo desta investigação é compreender como os recursos e capacidades estratégicos influenciam na vantagem competitiva em empresas de cervejas artesanais na cidade de Maringá. Para atingir esse objetivo, foi utilizado o modelo VRIO para averiguar o potencial desses recursos para a competitividade das cervejarias estudadas. 
A importância desse estudo decorre da evolução do mercado cervejeiro artesanal, que, em 2017, teve um crescimento de 37,7\% (MAPA, 2018). Nesse contexto, Maringá conta com quatro grandes empresas registradas no MAPA (2018) e no (NUCEM (2018), tornando possível uma pesquisa de campo para compreender como os recursos internos influenciam no desempenho das cervejarias artesanais. Visto que é um setor que está em crescimento, apresentando vez mais concorrentes no mercado, levantar informações sobre sua dinâmica operacional e competitiva se mostra válido. Ademais, não foram encontradas pesquisas aplicando o Modelo VRIO em cervejarias artesanais, o que indica um ineditismo na presente investigação.

Para atender o objetivo proposto, este artigo está dividido em cinco seções. Além desta introdução, a segunda parte está destinada ao referencial teórico, cuja base se constrói a partir dos pressupostos da VBR, envolvendo, os tipos de recursos, o modelo VRIO e aspectos de vantagem competitiva. Na terceira parte são apresentados os procedimentos metodológicos que foram utilizados para a coleta e análise dos dados. A quarta parte é destinada à análise dos resultados da pesquisa e, por fim, na última parte, é disponibilizada a conclusão do trabalho, seguida das referências utilizadas.

\section{REFERENCIAL TEÓRICO}

Para se identificar o desempenho superior das empresas, a partir de uma análise interna, proposta pela abordagem da VRB, é necessário entender alguns conceitos, como os tipos de recursos, o modelo VRIO, bem como os tipos de vantagem competitiva advindos da posse de recursos e capacidades por parte da empresa. Dessa forma, a seguir são referenciados alguns conceitos importantes para se atingir os objetivos deste trabalho.

\subsection{Visão baseada em recursos}

A Visão Baseada em Recursos (VBR) teve contribuições essenciais da economista Edith Penrose, na qual, em seu livro The theory of growth of the firm (1959), foi a pioneira em dar foco para a análise de aspectos internos do crescimento das empresas (POSSAS, 1985). Segundo Penrose (1959), uma firma é também uma coleção de recursos produtivos, cujo uso e disposição é determinada por decisões administrativas". Assim, o trabalho dos gestores consiste em explorar esses recursos produtivos e tomar decisões estratégicas. A partir disso, enfatiza-se os que recursos e capacidades distintos são capazes de gerar retornos para as empresas.

O termo VBR surgiu a partir de Wernefelt (1984), que desenvolveu a perspectiva de Penrose (1959) e apresentou, em seus estudos, a nomenclatura de Resourced Based View, originando o acrônimo RBV. Posteriormente, Barney (1991) sintetizou a VBR como um modelo de desempenho com foco nos recursos e capacidades que são controlados por uma empresa como fontes de vantagem competitiva. Na perspectiva desse autor, não só os recursos são importantes para a organização obter vantagem competitiva, mas também, e, principalmente, a forma como eles são usados dentro da empresa. 
Os recursos são considerados ativos tangíveis e intangíveis (BARNEY, 1991). De acordo com Barney e Hesterly (2012), enquanto os recursos tangíveis são aqueles mais visíveis e mais fáceis de identificar, os recursos intangíveis são mais difíceis de identificar e quantificar. Já as capacidades são vistas como um subconjunto dos recursos, que, quando combinadas com a utilização de recursos, possibilitam a criação e implementação de estratégias para a empresa (BARNEY; HESTERLY, 2012).

De acordo com Barney (1991, p. 101), “as empresas do mesmo setor são heterogêneas, pois controlam recursos e capacidades estratégicos internos diferentes". A partir dessa constatação, gerou-se um dos pressupostos básicos da VBR, que é o de heterogeneidade de recursos. Além disso, a heterogeneidade duradoura entre as empresas indica outro pressuposto básico, que é o da "imobilidade" dos recursos controlados (BARNEY, 1991), ou seja, os recursos não são facilmente transferíveis de uma empresa para a outra, indicando dificuldade na sua imitação.

\subsection{Tipos de recursos}

As firmas têm desempenho superior de seus competidores, pois possui algo "essencial", único à firma na qual é difícil seus concorrentes reproduzir (BARNEY, 1991). Os recursos podem ser classificados como financeiros, físicos, humanos e organizacionais. Os recursos financeiros incluem todo o dinheiro, seja de acionistas, credores, bancos, na qual as empresas utilizam para implementar estratégias (BARNEY; HESTERLY, 2012). Esse recurso inclui o capital próprio da empresa, suas dívidas e lucro retido (BARNEY, 1991).

Os recursos físicos, por sua vez, incluem a infraestrutura da empresa, sua tecnologia física que engloba máquinas e equipamentos, e a localização geográfica da organização, conforme indicado por Barney (1991). Esses recursos podem auxiliar no alcance e aprimoramento do produto, trazendo maior qualidade para o mesmo (BARNEY; ARIKAN, 2001). Já os recursos humanos englobam a experiência dos funcionários, treinamentos da organização, julgamentos, inteligência, relacionamentos interpessoais e conhecimento dos gestores e colaboradores da empresa (BARNEY, 1991). Barney e Arikan (2001) enfatizam que os recursos humanos podem contribuir na qualidade, no desenvolvimento, no aprimoramento e diferenciação dos produtos.

Por fim, os recursos organizacionais englobam as estruturas da empresa, como por exemplo, a forma na qual os relatórios são passados, assim como o planejamento e controle da firma (BARNEY, 1991). Incluem também a reputação da marca e sua credibilidade, e a política de remuneração (WERNERFELT, 1984; BARNEY, 1991, 1995). Esses recursos podem influenciar de maneira direta no produto ou serviço, como por exemplo, a influência da cultura organizacional e a reputação da marca no mercado, podendo gerar ou não vantagem competitiva para a firma (BARNEY; ARIKAN, 2001).

Segundo Peteraf (1993), as empresas com recursos superiores são às que apresentam maior lucratividade, pois elas têm custos mais baixos ao serem comparadas com as outras empresas. Nessa orientação, as firmas teriam desempenho superior aos seus competidores, pois possuiriam algo "essencial", único à firma, na qual é difícil seus concorrentes reproduzir (BARNEY, 1991). 


\subsection{VRIO}

Para entender como os recursos geram vantagem competitiva sustentável, Barney (1991) e Barney e Hesterly (2012) identificam a necessidade de um modelo teórico para tal entendimento, uma vez que nem todos os recursos das organizações tem potencial para gerar vantagem.

Nessa orientação, Barney e Hesterly (2012) propõem o Modelo VRIO, com o objetivo de relacionar a obtenção de vantagem competitiva sustentável com os recursos presentes em uma empresa, desde que dotados de atributos estratégicos. Atribui-se a questão do valor (V), da raridade (R), da imitabilidade imperfeita (I) e da organização dos recursos (O) como características necessárias para a obtenção de vantagem competitiva. Assim, surge a nomenclatura do modelo VRIO (Valor, Raridade, Imitabilidade e Organização). Para facilitar o entendimento dos atributos algumas perguntas devem ser levantadas, como pode ser observado no Quadro 1.

Quadro 1 - Questões Modelo VRIO

\begin{tabular}{|l|l|}
\hline Questão & \multicolumn{1}{|c|}{ Pergunta } \\
\hline Valor & $\begin{array}{l}\text { O recurso permite que a empresa explore uma oportunidade no ambiente e/ou } \\
\text { consegue neutralizar uma possível ameaça? O recurso permite aumentar os } \\
\text { lucros da empresa? }\end{array}$ \\
\hline Raridade & $\begin{array}{l}\text { O recurso é controlado atualmente apenas por uma pequena parte dos } \\
\text { concorrentes? }\end{array}$ \\
\hline Imitabilidade & $\begin{array}{l}\text { As empresas sem o recurso precisam de um grande investimento para obtê-lo } \\
\text { ou desenvolvê-lo? }\end{array}$ \\
\hline Organização & $\begin{array}{l}\text { A empresa está organizada (normas e procedimentos) para dar suporte à } \\
\text { exploração de seus recursos e capacidades? }\end{array}$ \\
\hline
\end{tabular}

Fonte: Adaptado de Barney (1991) e Barney e Hesterly (2012, p. 61).

O recurso é considerado valioso quando permite que a empresa explore uma oportunidade ou neutralize uma ameaça, reduzindo seus custos ou aumentando sua receita, ou seja, gerando maiores lucros. Se a empresa explorar esse tipo de recurso pode desenvolver uma força organizacional e, ao menos, uma paridade competitiva (BARNEY, 1991; BARNEY; HESTERLY, 2012).

A questão dos recursos raros é caracterizada por serem recursos de valor, que não são possuídos por um grande número de competidores. A firma deve explorar esse tipo de recurso que pode gerar vantagem competitiva, mesmo que temporária, como, por exemplo, o pioneirismo no setor. Por outro lado, conforme Barney e Hesterly (2012), se os recursos são controlados por muitos concorrentes gera paridade competitiva dentro do setor.

Os recursos difíceis de imitar, ou inimitáveis, por sua vez, são aqueles valiosos, raros e que apresentam dificuldades ou barreiras para serem imitados. De acordo com 
Barney (1991), há uma combinação de quatro fatores principais para a empresa alcançar a perspectiva de recursos difíceis de imitar.

O primeiro está relacionado com as condições históricas únicas inerentes a cada empresa, favorecendo a aquisição e desenvolvimentos de recursos em períodos anteriores, cuja perspectiva temporal impede a sua imitação pelos concorrentes no período atual (BARNEY, 1991; TEECE; PISANO; SHUEN, 1997). O segundo fator é a ambiguidade causal, na qual a firma não consegue identificar quais recursos controlados estão gerando vantagem competitiva. Dessa mesma forma, também há dificuldade para os concorrentes identificarem esses recursos e obterem fundamentos para sua replicação. O terceiro fator que dificulta a imitação de recursos é a complexidade social da firma, permeada pelas especificidades das suas relações internas, assim como sua cultura organizacional. Por fim, último fator que aumenta os custos para replicar o recurso são as patentes geradas pela empresa e legalmente protegidas (BARNEY; ARIKAN, 2001; BARNEY; HESTERLY, 2012).

Portanto, a vantagem competitiva sustentável é advinda de recursos que são valiosos, raros e difíceis de imitar, no sentido de os concorrentes terem desvantagem de custo para obter ou desenvolver esses mesmos recursos, por serem, no caso, recursos imperfeitamente imitáveis.

A organização é a última questão do modelo VRIO e indica se a empresa está organizada para aproveitar os seus recursos valiosos, raros e difíceis de imitar. De acordo com Barney e Hesterly (2012), essa questão está diretamente ligada à estrutura formal da empresa, aos seus sistemas de controles gerenciais, formais e informais, bem como às suas políticas de remuneração, ou seja, a forma como os empregados são remunerados.

Portanto, para identificação da vantagem competitiva da firma deve-se analisar os recursos a partir do modelo VRIO. O tipo de vantagem existente em cada empresa dependerá de como a firma administra, organiza e explora seus recursos de maneira única. Nesse caso, o desempenho superior aos concorrentes virá da organização que possui recursos valiosos, raros, difíceis de imitar e organizados.

\subsection{Vantagem competitiva}

Segundo Barney e Hesterly (2012), a vantagem competitiva ocorre quando a empresa tem maior valor econômico em relação aos seus concorrentes. $\mathrm{O}$ valor econômico é a diferença entre o valor percebido pelos clientes, que utilizam o produto ou serviço da empresa, e o custo econômico total desses produtos ou serviços.

Além da existência de vantagem, a empresa pode estar em desvantagem ou paridade competitiva em comparação aos seus concorrentes. As empresas podem ter paridade competitiva quando detêm o mesmo valor econômico que seus concorrentes. Por outro lado, a desvantagem competitiva ocorre quando as empresas têm menor valor econômico do que seus concorrentes (BARNEY; HESTERLY, 2012).

Conforme Barney (1991), além dessas ramificações, tem-se os tipos de vantagens competitivas temporárias e sustentáveis. Conforme o autor, as vantagens competitivas 
podem ser classificadas como temporárias quando a empresa utiliza uma estratégia que gera maior valor durante um curto período de tempo. No caso das sustentáveis, essas vantagens ocorrem quando a empresa consegue adotar uma estratégia que traz vantagem por um longo período do tempo, devido à dificuldade de cópia pelos concorrentes (BARNEY, 1991; BARNEY; HESTERLY, 2012; GUIMARÃES; SEVERO; VASCONCELOS, 2017).

Neste trabalho, utiliza-se a abordagem da VBR, tendo como foco o Modelo VRIO, para identificar a vantagem competitiva das empresas. Segundo Hitt et al. (2012) e Foss e Hallberg (2017) e Guimarães, Severo e Vasconcelos (2017), é fundamental, na perspectiva da VBR, definir o potencial dos recursos e capacidades da empresa em termos de identificar a vantagem competitiva e o potencial de desempenho que a empresa possui em relação aos concorrentes.

De acordo com Foss (1993) e Foss e Hallberg (2017), a presença ou não de recursos e seus atributos estão relacionados diretamente a existência ou não de vantagem competitiva. Destaca-se, por outro lado, que estudo sobre vantagem competitiva vai além dos recursos e capacidades internas e externas da empresa, abrangendo também o desenvolvimento de novos recursos e capacidades (TEECE; PISANO; SHUEN, 1997), assim como a combinação de habilidades, e a presença de recursos únicos que realce as vantagens da organização e dificulte a sua imitação pela concorrência (FOSS; HALLBERG, 2017)

\section{Procedimentos metodológicos}

Neste estudo, para a investigação e levantamentos dos dados, realizou-se uma pesquisa de natureza qualitativa, do tipo descritiva e com abordagem teórica empírica. A pesquisa qualitativa apresenta uma sequência de atividades que envolvem a síntese, categorização e interpretação de dados, propiciando a obtenção de detalhes intrínsecos a respeito dos fenômenos tácitos do objeto de estudo (STRAUSS; CORBIN, 2008). Dada à complexa compreensão de como os recursos e capacidades estratégicas influenciam na vantagem competitiva, a pesquisa de natureza qualitativa mostrou-se a mais adequada para identificar e captar as percepções, experiências, pontos de vista e opiniões dos entrevistados, como afirma Sampieri, Collado e Lucio (2013).

Além disso, a pesquisa é descritiva, uma vez que teve como objetivo descrever as características dos fenômenos estudados (GIL, 1999) . O tipo da pesquisa descritiva para esse estudo foi importante para detalhar os recursos estratégicos e como eles se manifestam nas empresas, assim como identificar a vantagem competitiva sob o enfoque da VBR e, mais especificamente, do modelo VRIO.

A abordagem é teórico-empírica, uma vez que os dados são fundamentados de acordo com os pressupostos teóricos, e os resultados são obtidos empiricamente. Os pressupostos teóricos consistem no desenvolvimento de um estudo sistematizado e baseado em toda teoria disponível em artigos, livros, jornais, revistas, sites ou outro meio acessível ao público (MARCONI; LAKATOS, 2006). Já os resultados empíricos ocorrem através da pesquisa a campo no local onde o objeto de estudo ocorre (GIL, 2008). 
Dessa forma, caracterizam-se como objeto de estudo dessa pesquisa as empresas de cervejas artesanais da cidade de Maringá-PR. Todas as empresas são de pequeno porte e produzem cerveja. Os serviços oferecidos, além da produção, é a venda (no caso da empresa $\mathrm{A}, \mathrm{B}$ e C), e o serviço de bar (para as empresas $\mathrm{B}, \mathrm{C}$ e D). O número de funcionários das empresas A, B, C e D, são, respectivamente, 6, 35, 30 e 16.

Quanto ao tipo de dados, foram coletados dados primários e secundários. Os dados primários foram coletados com os empresários de empresas de cervejas artesanais na cidade de Maringá. Isso porque, ao atuarem no ramo e estarem a frente de suas empresas de cervejas, esses empresários indicaram ter uma visão estratégia do negócio, necessária para atingir o objetivo proposto nesse trabalho. Assim, em cada empresa, foi entrevistado um sócio proprietário para obter as informações da pesquisa. Vale destacar que todos os gestores entrevistados possuíam ensino superior e tinham uma função ativa dentro das atividades da empresa. Ademais, todos possuíam experiência em produção de cerveja artesanal, visto que antes da abertura de suas respectivas empresas a produção já era realizada de modo caseiro. Também ocorreu a coleta de dados secundários, através de notícias e dados sobre o setor de cervejarias artesanais no Brasil.

Para a realização da coleta de dados primários, foram utilizadas entrevistas semiestruturadas, que aproximam o pesquisador e o objeto de pesquisa e facilitam o entendimento sobre o mesmo (CERVO; BERVIAN, 2002). Nessa orientação, foi previamente elaborado um roteiro contendo cinco partes, tendo como base os objetivos desse trabalho. A primeira parte foi destinada a perguntas relativas ao perfil do entrevistado, como por exemplo, profissão, gênero e renda familiar. Já na segunda parte foram elaboradas perguntas para identificar as atividades chaves da empresa. A terceira parte visou identificar os tipos de recursos e capacidades presentes nas atividades chaves da empresa. Na quarta parte, as perguntas foram focadas na identificação dos recursos a partir do Modelo VRIO. Por fim, na quinta parte as perguntas foram relacionadas à vantagem competitiva, buscando identificar como os entrevistados enxergavam a competitividade de suas empresas e quais recursos eles consideravam influentes na obtenção de vantagem competitiva.

A análise e interpretação dos dados utilizada foi o método de análise de conteúdo, proposto por Bardin (2006) como um conjunto de técnicas que possibilita a análise das comunicações. Segundo Malhotra (2012), a análise de conteúdo inclui a observação e a análise em si dos dados, atribuindo sentido interpretativo.

Segundo Bardin (2006) o método de análise de conteúdo pode ser dividido em três etapas: 1) pré-análise; 2) descrição analítica; 3 ) interpretação inferencial. A pré-análise tem como objetivo organizar todo o material a ser analisado, ou seja, consiste na organização do conteúdo dos dados coletados. Nesta etapa, as entrevistas semiestruturadas foram transcritas em um documento Word, e os dados foram organizados dentro de tópicos relacionados a cada conjunto de perguntas.

A segunda etapa, a de descrição analítica, tem como objetivo um caráter analítico sobre os objetivos específicos e o referencial teórico coletado (BARDIN, 2006). Assim foi realizado um estudo aprofundado do conteúdo principal da pesquisa. Para esse fim, 
utilizou-se o processo de codificação, na qual os relatos dos entrevistados foram agrupados em categorias que se relacionavam com o conteúdo da pesquisa, quais sejam: os recursos estratégicos, características dos recursos e o tipo de vantagem competitiva. Um esquema de análise representado visualmente a disposição das categorias e subcategorias é disponibilizado na Figura 1.

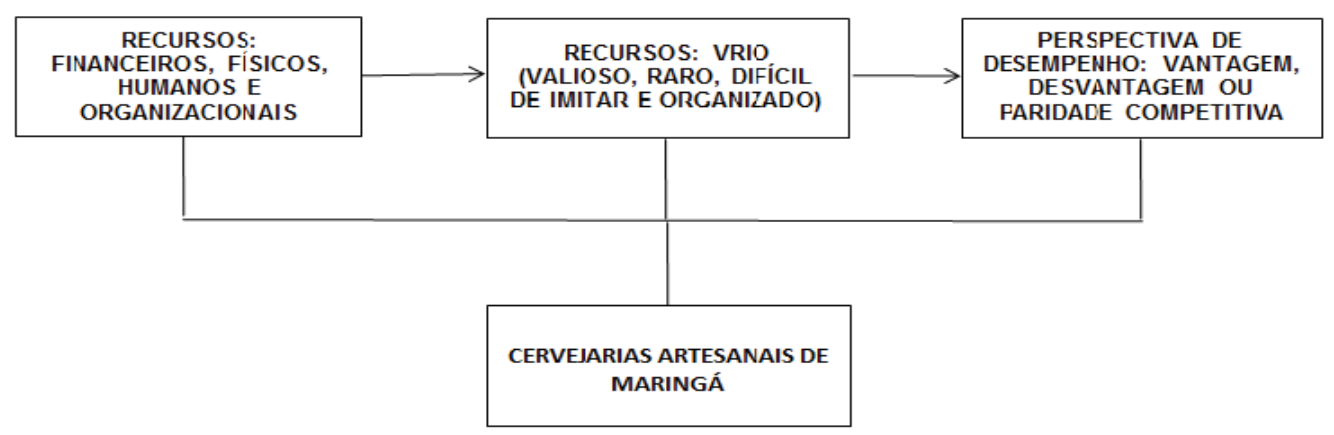

Figura 1 - Esquema de análise

Fonte: elaborado pelos autores.

Por fim, na última etapa, a de interpretação inferencial, o objetivo principal é a profundidade da análise por meio de inferências e reflexões diante dos dados a serem tratados, destacando as informações relevantes (BARDIN, 2006). Nesse caso, o estudo se iniciou com a categoria dos recursos estratégicos, analisando sua tipologia e características. Após essa etapa, foi avaliado a influência desses recursos na perspectiva de desempenho.

\section{ANÁlise dos RESUltados}

Essa seção tem o objetivo de apresentar os dados primários coletados, considerando as entrevistas semiestruturadas realizadas com diferentes proprietários de cervejarias artesanais na cidade de Maringá, bem como analisar as informações a partir do referencial teórico. Assim, buscou-se caracterizar os recursos estratégicos das empresas investigadas, visando identificar se esses são capazes de gerar vantagem. Conforme Hitt et al. (2012), Foss e Hallberg (2017) e Guimarães, Severo e Vasconcelos (2017), é importante, na perspectiva VBR, definir o potencial dos recursos e capacidades da empresa em termos de vantagem competitiva em relação aos seus concorrentes. Nesse sentido, é proposto o Quadro 2, visando fazer um comparativo entre o valor, raridade, imitabilidade e organização dos recursos presentes nas empresas investigadas. 
Quadro 2 - Recursos financeiros e vantagem competitiva das empresas investigadas

\begin{tabular}{|c|c|c|c|c|c|c|}
\hline Empresa & $\begin{array}{l}\text { Recurso da } \\
\text { Empresa }\end{array}$ & $\begin{array}{l}\text { O } \\
\text { Recurso é } \\
\text { Valioso? }\end{array}$ & $\begin{array}{l}\text { O Recurso } \\
\text { é Raro? }\end{array}$ & $\begin{array}{l}\text { O Recurso é } \\
\text { Dispendioso } \\
\text { de Imitar? }\end{array}$ & \begin{tabular}{|l} 
O Recurso \\
Está Sendo \\
Explorado \\
pela \\
Empresa? \\
\end{tabular} & $\begin{array}{l}\text { Categoria } \\
\text { Competitiva }\end{array}$ \\
\hline A & \multirow{3}{*}{$\begin{array}{l}\text { Capital de } \\
\text { Terceiros }\end{array}$} & Sim & Não & Não & Sim & PC \\
\hline B & & Sim & Não & Não & Sim & PC \\
\hline D & & Sim & Não & Não & Sim & PC \\
\hline B & Empréstimos & Sim & Não & Não & Sim & PC \\
\hline $\mathbf{C}$ & \multirow{2}{*}{ Capital Próprio } & Sim & Não & Não & Não & PC \\
\hline D & & Sim & Não & Não & Sim & PC \\
\hline $\mathrm{C}$ & Financiamento & Sim & Não & Não & Não & PC \\
\hline
\end{tabular}

Fonte: elaborado pelos autores.

Todas as empresas possuem recursos financeiros. Esses recursos são, notadamente, capital de terceiros, empréstimos, capital próprio e financiamento. Apesar de serem considerados valiosos para todos os entrevistados não são raros e nem difíceis de imitar. $\mathrm{O}$ que distingue internamente as empresas é a maneira de como elas estão organizadas a fim de explorar a utilização desses recursos.

Como se pode notar no Quadro 2, todas as empresas apresentam uma perspectiva de paridade competitiva em relação aos recursos financeiros utilizados, ou seja, criam o mesmo valor econômico que suas rivais, nos termos de Barney (1991), Barney e Hesterly (2012) e Guimarães, Severo e Vasconcelos (2017). O ponto a ser destacado é que as empresas A, B e D apresentam o quesito de organização para potencializar esse recurso, ao contrário a empresa $\mathrm{C}$ que ainda não está organizada para isso. Dentre os entrevistados, a empresa B é a mais organizada, com a presença de processos para controle desses recursos e boa comunicação entre os sócios.

Ao contrário dos recursos financeiros, os recursos físicos das empresas se distinguem mais, gerando vantagens notáveis para as empresas. Segundo Barney (1991), a empresa possui vantagem competitiva quando gera maior valor em relação aos seus concorrentes. A respeito das empresas, como é visto no Quadro 3, as empresas B e C apresentam vantagem competitiva temporária em relação aos recursos físicos. A primeira pela estrutura do bar, e a segunda pela engarrafadora e o filtro. Porém, por mais que existam recursos com potencial de vantagem, para que exista uma vantagem competitiva sustentável, é preciso que os recursos sejam difíceis de imitar e estejam organizados de forma a aproveitar o máximo de potencial competitivo (BARNEY, 1991; BARNEY; HESTERLY; 2012; GUIMARÃES; SEVERO; VASCONCELOS, 2017). 
Quadro 3 - Recursos Físicos e vantagem competitiva das empresas investigadas

\begin{tabular}{|c|c|c|c|c|c|c|}
\hline Empresa & $\begin{array}{l}\text { Recurso da } \\
\text { Empresa }\end{array}$ & $\begin{array}{l}\text { O Recurso } \\
\text { é Valioso? }\end{array}$ & $\begin{array}{l}\text { O } \\
\text { Recurso } \\
\text { é Raro? }\end{array}$ & $\begin{array}{l}\text { O Recurso é } \\
\text { Dispendioso } \\
\text { de Imitar? }\end{array}$ & $\begin{array}{l}\text { O Recurso } \\
\text { Está Sendo } \\
\text { Explorado } \\
\text { pela } \\
\text { Empresa? }\end{array}$ & $\begin{array}{l}\text { Categoria } \\
\text { Competitiva }\end{array}$ \\
\hline A & \multirow{4}{*}{ Localização } & Sim & Não & Não & Não & PC \\
\hline B & & Sim & Não & Não & Sim & PC \\
\hline C & & Sim & Não & Não & Sim & PC \\
\hline D & & Sim & Não & Não & Sim & PC \\
\hline A & \multirow{2}{*}{$\begin{array}{l}\text { Equipamentos } \\
\text { da produção } \\
\text { (desenvolvimento } \\
\text { próprio) }\end{array}$} & Sim & Sim & Sim & Sim & VCS \\
\hline D & & Sim & Sim & Sim & Sim & VCS \\
\hline A & \multirow{3}{*}{$\begin{array}{l}\text { Equipamentos } \\
\text { básicos da } \\
\text { produção }\end{array}$} & Sim & Não & Não & Sim & PC \\
\hline B & & Sim & Não & Não & Sim & PC \\
\hline $\mathbf{C}$ & & Sim & Não & Não & Sim & PC \\
\hline A & Produto inovador & Sim & Sim & Sim & Sim & VCS \\
\hline B & Estrutura do Bar & Sim & Sim & Não & Sim & VCT \\
\hline B & \multirow{2}{*}{ Matéria prima } & Sim & Não & Não & Sim & PC \\
\hline C & & Sim & Não & Não & Sim & PC \\
\hline $\mathrm{C}$ & Engarrafadora & Sim & Sim & Não & Sim & VCT \\
\hline $\mathrm{C}$ & Filtro & Sim & Sim & Não & Sim & VCT \\
\hline C & $\begin{array}{l}\text { Infraestrutura } \\
\text { Produção }\end{array}$ & Não & Não & Não & Não & DC \\
\hline
\end{tabular}

Fonte: elaborado pelos autores.

Os recursos físicos, de forma geral, não são raros e nem difíceis de imitar, pois existem fornecedores de equipamentos no mercado e, às vezes, as empresas utilizam o mesmo tipo de fornecedor. Por outro lado, um recurso físico de destaque, apontado pelo entrevistado da empresa $\mathrm{B}$, é a estrutura do segundo bar da empresa. Isso porque, essa estrutura possibilitou um aumento significativo em suas receitas, além de ser uma estrutura considerada pioneira no setor dentro da cidade. O entrevistado afirma: "pensando em uma arquitetura mais intima e menor, fomos o primeiro a fazer isso em termos de estrutura física, o primeiro modelo brewpub mais convencional dos Estados Unidos e Europa. De conceito, fomos o primeiro".

A respeito dos recursos físicos das empresas pesquisadas, somente as empresas A e $\mathrm{D}$ apresentam recursos com característica de vantagem competitiva sustentável. A empresa A e a D possuem equipamentos com desenvolvimento próprio, e esses equipamentos são considerados diferenciais na cidade. Além desse recurso, a empresa A também possui um produto inovador, cuja patente registrada dificulta a imitabilidade, sendo assim um destaque para a empresa A. Destaca-se que, dentre as empresas entrevistadas somente a empresa A possui presença de patente. 
Quadro 4 - Recursos Humanos e vantagem competitiva das empresas investigadas

\begin{tabular}{|c|c|c|c|c|c|c|}
\hline Empresa & $\begin{array}{l}\text { Recurso da } \\
\text { Empresa }\end{array}$ & $\begin{array}{l}\text { O Recurso é } \\
\text { Valioso? }\end{array}$ & $\begin{array}{c}\text { O Recurso } \\
\text { é Raro? }\end{array}$ & $\begin{array}{c}\text { O Recurso é } \\
\text { Dispendioso } \\
\text { de Imitar? }\end{array}$ & $\begin{array}{c}\text { O Recurso } \\
\text { Está Sendo } \\
\text { Explorado } \\
\text { pela } \\
\text { Empresa? }\end{array}$ & $\begin{array}{c}\text { Categoria } \\
\text { Competitiva }\end{array}$ \\
\hline A & \multirow{3}{*}{$\begin{array}{l}\text { Conhecimento } \\
\text { dos funcionários }\end{array}$} & Sim & Sim & Sim & Sim & VCS \\
\hline C & & Sim & Não & Não & Sim & PC \\
\hline D & & Sim & Não & Não & Não & PC \\
\hline A & \multirow{3}{*}{$\begin{array}{l}\text { Formação dos } \\
\text { sócios }\end{array}$} & Sim & Não & Não & Sim & PC \\
\hline B & & Sim & Não & Não & Sim & PC \\
\hline C & & Sim & Não & Não & Sim & PC \\
\hline B & $\begin{array}{c}\text { Experiência dos } \\
\text { sócios }\end{array}$ & Sim & Sim & Sim & Sim & VCS \\
\hline A & \multirow{4}{*}{$\begin{array}{c}\text { Cursos e } \\
\text { treinamentos }\end{array}$} & Sim & Não & Não & Sim & PC \\
\hline B & & Sim & Não & Não & Sim & PC \\
\hline C & & Sim & Não & Não & Não & PC \\
\hline D & & Sim & Não & Não & Não & PC \\
\hline B & \multirow{2}{*}{$\begin{array}{l}\text { Relacionamento } \\
\text { dos funcionários }\end{array}$} & Sim & Não & Não & Sim & PC \\
\hline C & & Sim & Não & Não & Sim & PC \\
\hline
\end{tabular}

Fonte: elaborado pela autores.

OQuadro 4 representa os recursos humanos e sua categorização. Como se pode perceber somente as empresas A e B têm vantagem com recursos humanos. Foi identificado que todas as empresas prezam por esse conhecimento, porém somente a empresa A têm seu diferencial relacionado ao recurso de conhecimento dos funcionários e consegue um destaque por ser uma empresa menor, e trabalhar somente com a parte de distribuição. Todos que trabalham na empresa A tem formação superior e o entrevistado é uma pessoa que valoriza muito os estudos e o conhecimento, disseminando isso na empresa. Para ele, os concorrentes podem ter conhecimento, porém a experiência de cada pessoa é diferente e isso gera o diferencial, pois sem o conhecimento intelectual não há geração de valor. Essa afirmação vai ao encontro do proposto por Barney e Arikan (2001), que os recursos humanos podem contribuir para a qualidade, desenvolvimento, aprimoramento e diferenciação dos produtos.

Para o entrevistado A o conhecimento não é fácil de ser copiado, conforme sua afirmação: "O mesmo conhecimento passado para duas pessoas diferentes gera um resultado diferente em cada pessoa, porque as pessoas aprendem baseado nas experiências que já teve e esse acúmulo de conhecimento é uma coisa que não se copia". Essa afirmação do entrevistado vai ao encontro do proposto por Barney (1991) que afirma que a complexidade social é um fator que faz a empresa alcançar o recurso difícil de imitar. Nesse caso, a cultura interna da empresa, em prezar pelo conhecimento e inteligência faz com que esse recurso, e a complexidade envolvida na sua construção, seja difícil de imitar. 
A empresa B também possui potencial para adquirir vantagem competitiva sustentável. Esse recurso é a experiência dos sócios, visto que é um diferencial na empresa e essa experiência impulsiona a organização da empresa e dá base para a expansão da mesma. Ademais, há uma cultura dentro da empresa B em incentivar a participação dos colaboradores em cursos e treinamentos. Por outro lado, as empresas C e D apresentam apenas recursos com paridade competitiva, pois os recursos são somente valiosos, mas não difíceis de imitar. Isso converge com a abordagem de Barney e Hesterly (2012) e Guimarães, Severo e Vasconcelos (2017), que enfatizam que os recursos somente valiosos apenas geram paridade competitiva no setor.

Quadro 5 - Recursos Organizacionais e vantagem competitiva das empresas investigadas

\begin{tabular}{|c|c|c|c|c|c|c|}
\hline Empresa & $\begin{array}{c}\text { Recurso da } \\
\text { Empresa }\end{array}$ & $\begin{array}{l}\text { O Recurso } \\
\text { é Valioso? }\end{array}$ & $\begin{array}{c}\text { O Recurso } \\
\text { é Raro? }\end{array}$ & $\begin{array}{c}\text { O Recurso é } \\
\text { Dispendioso } \\
\text { de Imitar? }\end{array}$ & $\begin{array}{c}\text { O Recurso } \\
\text { Está Sendo } \\
\text { Explorado } \\
\text { pela } \\
\text { Empresa? }\end{array}$ & $\begin{array}{c}\text { Categoria } \\
\text { Competitiva }\end{array}$ \\
\hline A & \multirow{3}{*}{ Marca } & Sim & Sim & Sim & Sim & VCS \\
\hline B & & Sim & Sim & Sim & Sim & VCS \\
\hline C & & Sim & Sim & Sim & Sim & VCS \\
\hline $\mathbf{A}$ & \multirow{2}{*}{$\begin{array}{c}\text { Cultura } \\
\text { Organizacional }\end{array}$} & Sim & Não & Não & Não & PC \\
\hline D & & Sim & Sim & Sim & Sim & VCS \\
\hline $\mathrm{A}$ & \multirow{2}{*}{$\begin{array}{c}\text { Clima } \\
\text { Organizacional }\end{array}$} & Sim & Sim & Não & Sim & VCT \\
\hline B & & Sim & Não & Não & Sim & PC \\
\hline $\mathbf{A}$ & \multirow{2}{*}{$\begin{array}{c}\text { Sistemas } \\
\text { de controle } \\
\text { gerencial }\end{array}$} & Não & Não & Não & Não & DC \\
\hline C & & Não & Não & Não & Não & DC \\
\hline B & $\begin{array}{l}\text { Planejamento } \\
\text { estratégico }\end{array}$ & Sim & Sim & Não & Sim & VCT \\
\hline B & $\begin{array}{c}\text { Estrutura dos } \\
\text { Departamentos }\end{array}$ & Sim & Sim & Não & Sim & VCT \\
\hline
\end{tabular}

Fonte: elaborado pelos autores.

Em relação aos recursos que geram vantagem competitiva, pode-se notar que as empresas A e B apresentam no total cinco recursos estratégicos com potencial de vantagem competitiva. Percebe-se, de acordo com os dados presentes no Quadro 5, que a empresa B se destaca nessa categoria de recursos. A empresa possui um recurso com potencial para gerar vantagem competitiva sustentável e outros dois com potencial para gerar vantagem competitiva temporária. A empresa B está organizada. Nota-se que a estratégia da empresa está relacionada diretamente com a marca da empresa, uma vez que,como afirma o entrevistado da Empresa B: "o intangível, a marca, vale mais do que nosso bens (sic) que estão aqui dentro, e para isso buscamos a perfeição e a melhoria continua". 
Um recurso a se destacar na empresa A é o clima organizacional. O relacionamento interpessoal dos funcionários da empresa A contribui para um clima organizacional favorável. Os funcionários são próximos e os sócios sempre estão presentes. Segundo entrevistado existe uma emoção em se trabalhar com produção de cervejas. Esse recurso gera maior satisfação dos funcionários, e impacta na eficiência do trabalho. Essa afirmação segue o proposto por Barney e Hesterly (2011), na qual o capital humano e a cultura organizacional poderá ser um fator que aproveita habilidades e experiência dos funcionários de forma a criar a complexidade social e contribuir para obtenção de vantagem competitiva.

Vale ressaltar que a empresa $\mathrm{D}$ apesar de possuir apenas dois recursos que geram vantagem, essa vantagem tem potencial de ser sustentável. Já a empesa $\mathrm{C}$ possui apenas um recurso na categoria de vantagem competitiva sustentável. Essa afirmação corresponde ao argumento de Barney (1991) e Barney e Hesterly (2012) de que se a empresa possui recursos internos que são valiosos e raros, e difíceis de imitar ela terá vantagem competitiva sustentável. Porém, identificou-se que a empresa $\mathrm{C}$ não explorou o suficiente o pioneirismo no setor e não se destacou por esse recurso.

A empresa A se distingue das outras empresas, pois a empresa trabalha apenas com a produção e distribuição da cerveja, não possuindo, como as outras empresas, um brewpub. De acordo com as respostas do entrevistado da empresa A, o principal recurso que gera vantagem competitiva na empresa é o capital humano. Porém, de acordo com os dados obtidos percebe-se que os recursos físicos geram um impacto maior na empresa $\mathrm{A}$ no que tange à inovação. Diferente das outras cervejarias, ficou evidente a importância e disseminação da inovação dentro da empresa A. Segundo o entrevistado a estratégia da empresa é ser sempre pioneira e focar na inovação, principalmente em produtos, alcançável devido aos recursos físicos presentes.

$\mathrm{Na}$ opinião e visão do sócio da empresa $\mathrm{B}$, o recurso que mais gera vantagem competitiva na empresa também são os recursos humanos, mas, em relação ao diferencial da empresa, segundo entrevistado, o diferencial é na qualidade dos produtos. Para o entrevistado da empresa B: "procuramos nos diferenciar mais em relação à qualidade dos nossos produtos, aos espaços que cria, buscamos uma boa experiência aonde envolva estrutura, atendimento e produto, a gente não vende cerveja, a gente vende experiência". O investimento nos espaços internos, o que faz com que a empresa ganhe destaque no mercado maringaense e conquiste novos clientes para a empresa. Esta organização estruturada gera suporte para a empresa oferecer a experiência completa para o cliente.

Quando questionado qual é o grupo de recursos que é mais determinante na aquisição de vantagem competitiva, o entrevistado da empresa $\mathrm{C}$ também determinou os recursos humanos. Porém, a pesquisa evidencia os recursos físicos. Para a empresa $\mathrm{C}$ a principal estratégia utilizada para gerar vantagem competitiva é o custo-benefício do produto, uma vez que preza pela cerveja boa com um preço acessível, sendo que essa estratégia é possível devido o volume de produção. Ficou evidente que a empresa $\mathrm{C}$ está focando mais em aumentar a sua capacidade produtiva, e por isso está investindo em seus recursos físicos. 
Assim como as empresas A, B e C, para o entrevistado da empresa D o grupo de recursos que gera maior vantagem para sua empresa são os humanos. Todavia, os dados da pesquisa indicam que a empresa $\mathrm{D}$ possui destaque em seus recursos físicos e organizacionais. A empresa D não possui uma estratégia formalizada, segundo o entrevistado: "para mim a minha estratégia, [...], é ter um bom atendimento, um bom produto então é uma estratégia que todos buscam". Para ele a empresa possui duas vantagens: "localização, que eu acho que é uma vantagem e um preço pelo produto justo".

Para Barney e Hesterly (2011), o processo de gestão estratégica visa que a empresa escolha e implemente uma estratégia que irá gerar maior valor econômico que duas concorrentes. Foi identificado no setor de cervejarias artesanais que há certa abertura entre as cervejarias, uma vez que elas se uniram para propor uma experiência diferente ao consumidor, e, também, para lutarem contra as grandes marcas de cervejas industrializadas. Diante disso, a questão da imitabilidade porventura acontece entre essas empresas. Elas realizam benchmarking e algumas ajudam empresas novas a se estabelecerem no mercado. Diante dessa questão, as empresas precisam procurar seu diferencial de atuação próprio que faça com que os clientes procurem suas marcas. De acordo com os dados financeiros disponibilizados pelos entrevistados, o Quadro 6 compara o faturamento bruto das empresas com a venda de cerveja mensal.

Quadro 6 - Faturamento bruto mensal

\begin{tabular}{|c|c|c|c|c|c|}
\hline Empresa & Vendas em litro/mês & \multicolumn{2}{|c|}{ Preço médio do litro } & \multicolumn{2}{|c|}{ Faturamento mensal } \\
\hline A & $8.000 \mathrm{~L}$ & $\mathrm{R} \$$ & 13,00 & $\mathrm{R} \$$ & $104.000,00$ \\
\hline B & $10.000 \mathrm{~L}$ & $\mathrm{R} \$$ & 25,00 & $\mathrm{R} \$$ & $250.000,00$ \\
\hline $\mathrm{C}$ & $15.000 \mathrm{~L}$ & $\mathrm{R} \$$ & 7,00 & $\mathrm{R} \$$ & $105.000,00$ \\
\hline $\mathrm{D}$ & $5.000 \mathrm{~L}$ & $\mathrm{R} \$$ & 24,00 & $\mathrm{R} \$$ & $120.000,00$ \\
\hline
\end{tabular}

Fonte: elaborado pelos autores.

Como pode-se perceber, a empresa B possui um faturamento maior em relação às outras empresas, e seus recursos de destaque são os organizacionais. Os recursos organizacionais são os principais diferenciais para a empresa B: a maneira que está estruturada, com processos formais, cargos definidos e planejamento estratégico faz com que os sócios e funcionários trabalhem com direcionamento e consigam expandir a empresa, contribuindo para o destaque da empresa B no mercado e sua marca consolidada. Essa afirmação vai ao encontro com o exposto por Peteraf (1993), que as empresas com recursos superiores são as que apresentam maior lucratividade.

Apesar da empresa A apresentar um alto número de recursos, e ter quatro recursos com potencial para gerar vantagem competitiva sustentável, ela se apresenta como a empresa com menor faturamento bruto. Porém, vale ressaltar que é a única empresa pesquisada que não trabalha no estilo de brewpub, ou seja, a empresa trabalha somente com a distribuição dos produtos. 
A empresa $\mathrm{D}$ é nova no mercado, porém apresenta o $2^{\circ}$ maior faturamento. Isso está relacionado com a organização da empresa e com a clareza dos sócios em relação ao seu negócio. Com apenas seis meses de funcionamento a empresa possui dois recursos com potencial para alcançar vantagem competitiva sustentável. A cultura organizacional da empresa é consolidada, e todos os colaboradores trabalham e são cobrados a se manterem focados nela, sendo esse o principal recurso que faz com que a empresa tenha diferencial no mercado em pouco tempo. Os recursos da empresa D são eficientes e a cultura focada para o cliente gera satisfação. Segundo Peteraf (1992), a eficiência dos recursos existe quando as empresas têm recursos que são capazes de produzir mais eficientemente, por outro lado, a eficácia surge quando os recursos são capazes de trazer mais satisfação para os clientes. Essa afirmação é vista na empresa D com seus recursos de cultura organizacional e o desenvolvimento dos equipamentos.

A empresa $\mathrm{C}$, apesar de ser pioneira com o brewpub apresenta apenas um recurso com potencial para vantagem competitiva sustentável. É a empresa que tem o preço cobrado pelo litro mais barato, e esse fator influencia no seu desempenho financeiro que está em $3^{\circ}$ lugar. É a empresa com maior capacidade produtiva, porém, seu preço está abaixo dos seus concorrentes, e isso converge com a sua estratégia de oferecer o melhor custo-benefício.

Em suma, percebe-se que a empresa A busca inovação de produtos, ou seja, por ser uma empresa que está focada somente em vendas de distribuição, foca suas atividades para desenvolver novos produtos. Um ponto a se destacar é o conhecimento do sócio entrevistado que fica evidente por ser a única empresa com um produto inovador que ainda não existe no mercado. Por outro lado, percebe-se que a empresa B está mais estruturada internamente e o foco é na qualidade de produtos. Fica claro que a estratégia da empresa é de expansão e de investimento em novos negócios, e esse é um dos principais diferencias da empresa. $\mathrm{O}$ novo conceito de brewpub que a empresa trouxe para Maringá vem conquistando cada vez mais os moradores da cidade.

Em relação à empresa $\mathrm{C}$, percebe-se que o foco é na distribuição dos produtos, mesmo por ser pioneira no segmento de brewpub, nota-se que o foco ficou no custo-benefício do produto para vender em grandes escalas. Já a empresa D surpreende pelos, apenas, seis meses no mercado. Os sócios têm boa organização e já começaram bem o negócio, sendo que o foco para eles é o cliente e sua satisfação.

\section{Conclusões e Propostas}

A presente investigação teve como objetivo compreender como os recursos e capacidades estratégicos influenciam na vantagem competitiva em empresas de cervejas artesanais na cidade de Maringá. Dessa forma, constatou-se que as empresas entrevistadas possuem recursos heterogêneos que influenciam o desempenho da organização e geram vantagens para suas respectivas empresas. Segundo os dados levantados, a empresa que possui maior faturamento, a empresa $\mathrm{B}$, também é a empresa que tem o maior número de recursos que geram vantagem competitiva. 
Nesse processo, pode-se concluir que os recursos físicos e organizacionais são os mais influentes na geração de competitividade para as empresas. O recurso mais determinante na aquisição de vantagem competitiva para a empresa A são os físicos e os organizacionais, sendo que os físicos são os que geram maior diferencial para a empresa, estando ligados a sua capacidade inovativa. Para a empresa B, os recursos organizacionais são os que geram maior vantagem competitiva em relação aos seus concorrentes, porém, a empresa também apresenta bons recursos humanos e físicos. Já para a empresa $C$ são os recursos físicos que se destacam e geram vantagem competitiva e, por fim, na empresa $\mathrm{D}$, são os recursos físicos e organizacionais que mais geram vantagem competitiva.

Foi identificado que o mercado cervejeiro em Maringá é receptivo, uma vez que as empresas pioneiras desenvolvem cursos e ajudam outras empresas a se estabelecerem. Apesar de essa aproximação gerar certa imitabilidade entre as empresas, cada uma segue seu modelo de negócios. Portanto, as empresas podem apresentar alguns recursos iguais, ou parecidos, porém suas estratégias são diferentes e nota-se que estão seguindo caminhos distintos. De qualquer forma, o objetivo delas, ao final, é o mesmo: oferecer experiência para o consumidor e não somente um copo gelado de cerveja.

As limitações desse trabalho relacionam-se a visão unilateral dos sócios das empresas investigadas, além da dificuldade em coletar os indicadores financeiros dessas empresas. Assim, como sugestão para próximas pesquisas, propõe-se integrar uma pesquisa com outros funcionários da empresa, que não sócios, para identificar recursos e capacidades além das coletadas. Outro ponto de sugestão é a realização de uma pesquisa com a perspectiva do cliente e sua satisfação, para complementar opiniões e fazer comparativos com as perspectivas dos sócios entrevistados. Por fim, apesar das limitações inerentes à pesquisa, essa investigação teve o intuito de enriquecer os estudos na área de estratégia, contribuindo para fomentar discussões sobre a competitividade do setor de cervejas artesanais no País.

\section{REFERÊNCIAS}

ABRACERVA. Número de cervejarias artesanais no Brasil cresce 37,7\% em 2017. Disponível em: http://abracerva.com.br/2018/02/16/numero-de-cervejarias-artesanais-no-brasil-cresce-377em-2017/. Acesso em: 24/07/2018.

AMIT, R. P.; SCHOEMAKER, J. H. Strategic assets and organizational rent. Strategic Management Journal, v. 14, p. 33-46, 1993.

ANDRADE, M. Introdução à metodologia do trabalho científico. $8^{\mathrm{a}}$ ed. São Paulo: Atlas, 2007. BARDIN, L. Análise de conteúdo (L. de A. Rego \& A. Pinheiro, Trads.). Lisboa: Edições 70. 2006.

BARNEY, J. B. Is the resource based "view" a useful perspective for strategic management research? Yes. Academy of Management Review, v. 25, n. 1, p. 41-56, 2001

BARNEY, J. Firm resources and sustained competitive advantage. Journal of Management. v. 7, n.1, p. 99-120, 1991.

BARNEY, J. Strategic factor markets: expectations, luck and business strategy. Management Science, v. 32, n. 10, p. 1231-1241, 1986. 
BARNEY J. B.; ARIKAN, A. M. The Resource-Based-View: Origins and Implications. Handbook of Strategic Management, Forthcoming, 2001.

BARNEY, J.; HESTERLY, W. S. Administração estratégica e vantagem competitiva. São Paulo: Pearson Education do Brasil, 2012.

CERVO, A. L. BERVIAN, P. A. Metodologia científica. 5.ed. São Paulo: Prentice Hall, 2002.

CRUBELLATE, J. M.; PASCUCCI, L.; GRAVE, P. S. Contribuições para uma visão baseada em recursos legítimos. Revista de Administração de Empresas, v. 48, n. 4, 2008.

COSTA, E. A. Gestão Estratégica - Da empresa que temos para a empresa que queremos. $2^{\mathrm{a}}$ ed. [S.1]: Saraiva, 2007.

FOSS, N. J.; LANGLOIS, R. N. Capabilities and governance: the rebirth production in the theory of economic organization. DRUID Working Paper n. 97-2. Copenhagen: Copenhagen Business School, 1997, p. 1-33.

GOHR, C. et al. Recursos estratégicos e vantagem competitiva: aplicaçäo do modelo VRIO em uma organizaçäo do setor sucroalcooleiro. 2011. 12f. Tese de conclusäo do curso -

Universidade Federal da Grande Dourados, Dourados, 2011.

GUimarÃES, J. C. F.; SEVERO, E. A.; VASCONCELOS, C. R. M. Vantagem Competitiva Sustentável: uma pesquisa em empresas do Sul do Brasil. Brazilian Business Review, v. 14, Vitória, mai/jun, 2017.

KRETZER, Jucélio. A importäncia da visäo baseada em recursos na explicaçäo da vantagem competitiva. 2006. 24f. Tese de doutorado - UFSC, Santa Catarina, 2006.

LEARNED, E. P.; CHRISTENSEN, C. R.; ANDREWS, K.; GUTH, W. D. Business policy. Homewood:Irwing, 1969.

MALHOTRA, N. K. Pesquisa de Marketing. Uma orientação aplicada. Tradução de Lene Belon Ribeiro, Monica Stefani. 6. ed. Porto Alegre: Bookman, 2012.

MARCUSSO, E; MULLER, C. A cerveja no Brasil: O ministério da agricultura informando e esclarecendo. Ministério da Agricultura, Pecuária e Abastecimento. 2017.

MARINGÁ POST. Com oito fábricas, Maringá já produz 165 mil litros de cerveja artesanal por mês, deve passar de um milhão em 2020 e trabalha para criar uma rota cervejeira de respeito. Disponível em: https://maringapost.com.br/guias/2018/04/19/com-oito-fabricas-maringaja-produz-165-mil-litros-de-cerveja-artesanal-por-mes-deve-passar-de-um-milhao-em-2020-etrabalha-para-criar-uma-rota-cervejeira-de-respeito/. Acesso em: 04/07/2018.

MASON, E. S. Price and production policies of large scale enterprises. American Economic Review, n. 29, p. 61-74, 1939.

MINTZBERG, H.; LAMPEL, J.; QUINN, J.; GHOSHAL. O processo da Estratégia - conceitos, contextos e casos selecionados. $4^{\mathrm{a}}$ ed. Porto Alegre: Bookman, 2006.

NOTHAFT, A. Brazil's Craft Brewing Scene. The New Brew International, Boulder, v.2, n.2, p.10- 15, 1998 a.

O GLOBO. O crescimento de 39,6\% no número de cervejarias em 2016 é espetacular.

Disponível em: https://blogs.oglobo.globo.com/aqui-se-bebe/post/artigo-o-crescimento-de-396no-numero-de-cervejarias-em-2016-e-espetacular.html. Acesso em: 04/07/2018.

PENROSE, E. The theory of the growth of the firm. Oxford: Basil Blackwell, 1959. 
PETERAF, M. A. The cornerstones of competitive advantage: a Resource-Based View. Strategic Management Journal, v. 14, p. 179-191, 1993.

PORTER, M. How Competitive Forces Shape Strategy. Harvard business review, 57, 1979.

PORTER, M. Vantagem competitiva, criando e sustentando vantagem no setor. $37^{\circ}$ ed. [S.1.]: Elsevier, 1985.

POSSAS, M. Estruturas de mercado em oligopólio. São Paulo: Hucitec, 1985.

PROCERVA. Estudo mapeia o setor de microcervejarias artesanais no PR. Disponível em: http://www.procerva.com.br/noticias/. Acesso em: 04/07/2018.

SAMPIERI, R.; COLLADO, C.; LUCIO, M. Metodologia de Pesquisa. $5^{\circ}$ ed. Porto Alegre: Penso, 2013.

STRAUSS, A.; CORBIN, J. Pesquisa Qualitativa - Técnicas e procedimentos para o desenvolvimento de teoria fundamentada. $2^{\mathrm{a}}$ ed. Porto Alegre: Artmed, 2008.

TEECE, D. Capturing Value from Knowledge Assets: The New Economy, Markets for KnowHow, and Intangible Assets. California Management Review, v. 40, n. 3, 1998.

TEECE, D. J. Economic analysis and strategic management. California Management Review, v. 25, p. 87-110, 1984.

TEECE, D; PISANO, G. SCHUEN, A. Dynamic capabilities and strategic management.

Strategic Management Journal. v. 18, n.7, p. 509-533, 1997.

TRIVINOS, A. W. S. Introdução à pesquisa em ciências sociais. São Paulo: Atlas, 1987.

WERNERFELT, B. A resource-based view of the firm. Strategic Management Journal. v. 5, p. 171-180, 1984.

\section{Roteiro Entrevista}

$\Rightarrow \quad$ Perfil do entrevistado

$\Rightarrow \quad$ Perfil da empresa

$\Rightarrow \quad$ Perguntas relacionadas aos tipos de recursos

$\Rightarrow \quad$ Perguntas relacionadas ao modelo VRIO

$\Rightarrow \quad$ Perguntas relacionadas ao tipo de vantagem competitiva

Perfil do entrevistado:

1) Nome/ Gênero/ Escolaridade?

2) Cargo na empresa? Tempo no cargo?

3) Já possuía experiência nessa área?

Perfil da empresa:

- Localização da empresa: 
4) Quantos anos a empresa está no mercado? Qual o porte da empresa?

5) Por quantos sócios-proprietário a empresa é formada? Qual a quantidade de funcionários?

6) Quais são as atividades chave da empresa?

7) Quais são os tipos de produtos oferecidos? Quais são os tipos de serviço oferecidos? (Funciona só com venda, tem bar etc.)

8) Qual a capacidade produtiva mensal de cervejas? Qual faturamento mensal da empresa?

9) Participam ou participaram de alguma premiação em concurso? Já receberam alguma premiação?

\section{Tipos de recursos e VRIO:}

- Introduzir o assunto e explicar os recursos:

10) Quais são os recursos financeiros da empresa? (capital de terceiros, capital próprio, precisa de financiamento?).

10.1 Esses recursos que você falou, acredita que eles impactam nos seus custos ou receitas? Você acredita que somente a sua empresa têm esse tipo de recurso, ou identifica que a concorrência também detém desse recurso? Você considera pioneiro na utilização desse recurso? Acredita que o relacionamento de seus funcionários e a cultura da empresa contribui para deixar esse recurso difícil de imitar pelos concorrentes? Há algum tipo de patente em relação a esses recursos? Quem faz a utilização desse recurso? (organização - estrutura) Como acontece a comunicação? Há processos envolvidos para controlar esses recursos? (Formais: orçamento, relatórios de vendas, desempenho e produtividade; Informais: relações, cultura organizacional - garantir e monitorar as pessoas). E como é a remuneração envolvendo esses recursos? Há algum incentivo ou benefício?

11) Quais são os recursos físicos da empresa? (como a infraestrutura, tecnologia, máquinas e equipamentos, localização)

11.1 Esses recursos que você falou, acredita que eles impactam nos seus custos ou receitas? Você acredita que somente a sua empresa têm esse tipo de recurso, ou identifica que a concorrência também detém desse recurso? Você considera pioneiro na utilização desse recurso? Acredita que o relacionamento de seus funcionários e a cultura da empresa contribui para deixar esse recurso difícil de imitar pelos concorrentes? Há algum tipo de patente em relação a esses recursos? Quem faz a utilização desse recurso? (organização - estrutura) Como acontece a comunicação? Há processos envolvidos para controlar esses recursos? (Formais: orçamento, relatórios de vendas, desempenho e produtividade; Informais: relações, cultura organizacional - garantir e monitorar as pessoas). E como é a remuneração envolvendo esses recursos? Há algum incentivo ou benefício?

12) Quais são os recursos humanos da empresa?

12.1 Esses recursos que você falou, acredita que eles impactam nos seus custos ou receitas? Você acredita que somente a sua empresa têm esse tipo de recurso, ou identifica que a concorrência também detém desse recurso? Você considera pioneiro na utilização desse recurso? Acredita que o relacionamento de seus funcionários e a cultura da empresa contribui para deixar esse recurso difícil de imitar pelos concorrentes? Há algum tipo de patente em relação a esses recursos? Quem faz a utilização desse recurso? (organização - estrutura) Como acontece a comunicação? Há processos envolvidos para controlar esses recursos? (Formais: orçamento, relatórios de vendas, desempenho e produtividade; Informais: relações, cultura organizacional - garantir e monitorar as pessoas). E como é a remuneração envolvendo esses recursos? Há algum incentivo ou benefício? 
13) Quais são os recursos organizacionais da empresa?

13.1 Esses recursos que você falou, acredita que eles impactam nos seus custos ou receitas? Você acredita que somente a sua empresa têm esse tipo de recurso, ou identifica que a concorrência também detém desse recurso? Você considera pioneiro na utilização desse recurso? Acredita que o relacionamento de seus funcionários e a cultura da empresa contribui para deixar esse recurso difícil de imitar pelos concorrentes? Há algum tipo de patente em relação a esses recursos? Quem faz a utilização desse recurso? (organização - estrutura) Como acontece a comunicação? Há processos envolvidos para controlar esses recursos? (Formais: orçamento, relatórios de vendas, desempenho e produtividade; Informais: relações, cultura organizacional - garantir e monitorar as pessoas). E como é a remuneração envolvendo esses recursos? Há algum incentivo ou benefício?

\section{Vantagem Competitiva:}

14) A empresa utiliza algum tipo de estratégia para obter vantagem competitiva? Qual?

15) Quantos litros de cerveja vocês vendem mensal? Qual o preço cobrado por litro? Qual o faturamento mensal com essas vendas?

16) Como você acha que está seu preço, comparado com os concorrentes?

17) Vocês coletam satisfação dos clientes em relação aos produtos e serviços oferecidos? Qual a satisfação deles?

18) Na sua visão, qual é o diferencial da sua empresa?

19) Você acha que a empresa hoje apresenta vantagem competitiva em relação aos seus concorrentes? Quais as razões que levam a chegar a essa conclusão?

20) Dentre esses recursos que você falou (financeiros, físicos, humanos e organizacionais), qual você acredita ser o tipo mais determinante na aquisição de vantagem competitiva pela empresa?

*Pedir permissão para tirar foto do cardápio de cervejas

Submetido em: 7-4-2020

Aceito em: 31-3-2021 